DOI: $10.34220 /$ issn.2222-7962/2020.4/18

УДК $630 * 377.44$

РАЗРАБОТКА УЗЛА СОЧЛЕНЕНИЯ ЛЕСНОЙ ПОГРУЗОЧНО-ТРАНСПОРТНОЙ МАШИНЫ

\author{
кандидат технических наук, доцент В.Е. Клубничкин ${ }^{1}$ \\ кандидат технических наук, доцент Е.Е. Клубничкин ${ }^{1}$ \\ ведущий инженер-конструктор А.Ю. Горбунов ${ }^{2}$ \\ кандидат технических наук, доцент Д.Ю. Дручинин ${ }^{3}$ \\ 1 - Мытищинский филиал ФГБОУ ВО «Московский государственный технический университет \\ имени Н.Э. Баумана», г. Мытищи, Российская Федерация \\ 2 - ФГБОУ ВО «Московский государственный технический университет имени Н.Э. Баумана», \\ г. Москва, Российская Федерация \\ 3 - ФГБОУ ВО « Воронежский государственный лесотехнический университет имени Г.Ф. Морозова», \\ г. Воронеж, Российская Федерация
}

В статье представлена структурная гидравлическая схема системы рулевого управления разрабатываемой погрузочно-транспортной машины (ПТрМ). Описаны основные компоненты, из которых состоит рулевое управление машины. Выбрана схема узла шарнирного сочленения и определен радиус и коридор поворота ПТрМ. В работе был проведен кинематический анализ узла шарнирного сочленения ПТрМ представляющий собой определение предельных углов складывания узла сочленения и хода силовых гидроцилиндров по разработанным электронным твердотельным моделям. Определен момент сопротивления, потребный для складывания машины полной массы на месте на твердой опорной поверхности с высоким коэффициентом сцепления с учетом взаимодействие шин с опорной поверхностью при помощи полуэмпирической модели Пачейки MF-Tуге 6.1. Параметры модели для шины 750/55-26.5. Создана динамическая модель лесной ПТрМ имеющая следующие особенности: все звенья динамической системы абсолютно жесткие; все колеса не заторможены и вращаются; трение в шарнирах отсутствует; груз (сортименты) смоделирован абсолютно жесткий единым телом; моделирование производилось для полностью груженой ПТрМ; дифференциалы в мостах не заблокированы (свободные). Представлены вертикальные нагрузки в пятне контакта колес переднего и заднего мостов, а также боковые реакции в пятне контакта колес переднего и заднего мостов.

Ключевые слова: рулевое управление, узел сочленения, гидроцилиндр, погрузочно-транспортная машина, кинематический анализ 


\title{
DEVELOPMENT OF THE FORWARDER ARTICULATION JOINT
}

\author{
$\mathrm{PhD}$ (Engineering), Associate Professor V.E. Klubnichkin ${ }^{1}$ \\ $\mathrm{PhD}$ (Engineering), Associate Professor E.E. Klubnichkin ${ }^{1}$ \\ Leading design engineer A.Yu. Gorbunov ${ }^{2}$ \\ $\mathrm{PhD}$ (Engineering), Associate Professor D.Yu. Druchinin ${ }^{3}$
}
1 - Mytishi branch of FSBEI HE "Bauman Moscow State Technical University", Mytishi, Russian Federation
2 - FSBEI HE "Bauman Moscow State Technical University", Moscow, Russian Federation
3 - FSBEI HE "Voronezh State University of Forestry and Technologies named after G.F. Morozov", Voronezh, Russian Federation

\begin{abstract}
The article presents a structural hydraulic diagram of the steering system of the developed forwarder. The main components that make up the steering of the machine are described. The scheme of the articulated joint was selected and the radius and the corridor of the forwarder's turn were determined. In the work, a kinematic analysis of the articulated joint of the forwarder was carried out, which is the determination of the limiting angles of folding of the articulation unit and the stroke of the hydraulic power cylinders according to the developed electronic solid models. The moment of resistance required to fold the car of full weight in place on a solid supporting surface with a high coefficient of adhesion, taking into account the interaction of tires with the supporting surface, was determined using the semiempirical model of Packa MF-Tire 6.1. Model parameters for tire 750/55-26.5. A dynamic model of a forwarder has been created with the following features: all links of the dynamic system are absolutely rigid; all wheels are not braked and rotate; there is no friction in the hinges; the load (assortments) is modeled absolutely rigid by a single body; the simulation was done for a fully laden forwarder; axle differentials are not locked (free). The vertical loads in the contact patch of the front and rear axles, as well as lateral reactions in the contact patch of the front and rear axles are presented.

Keywords: soil cutting, soil environment; working body; spherical disk, modeling, finite element method, spherical particle

\section{Введение}

Обзор и анализ конструкций систем управления тракторов с шарнирно-сочлененной рамой показал, что они обладают рядом преимуществ по сравнению с управляемыми колесами особенно ярко выраженными на колесных тракторах с большими колесами, работающих в условиях лесного бездорожья [1-3].

В работах [4-7] рассматриваются вопросы создания и исследования компоновки специальных колесных лесных тракторов с шарнирной рамой, представлены исследования направленные на повышение усталостной долговечности шарнирносочлененных несущих конструкций, применяемых в многооперационных лесозаготовительных машинах.

Проведенный обзор и анализ конструкций систем управления колесных шарнирносочлененных машин, показал, что наибольшее рас-

пространение получили системы управления с гидравлическим приводом.

В соответствии с требованиями Технического задания проекта рулевое управление (РУ) лесной погрузочно-транспортной машины (ПТрМ) должно быть электромеханическим или гидравлическим. Поворот ПТрМ должен осуществляться за счет складывания несущей системы в горизонтальной плоскости в узле сочленения.

Привод рулевого управления ПТрМ - гидрообъемный. Максимальные углы поворота узла сочленения составляют 44 градуса. Обратная связь рулевого управления - гидравлическая.

Рулевое управление состоит из следующих компонентов: насос (совместно питающий систему рулевого управления, рабочего оборудования, систему стабилизации кабины, тормозную систему и системы блокировки и переключения передач трансмиссии), гидроцилиндры поворота, насос-
\end{abstract}

Лесотехнический журнал 4/2020 
дозатор, усилитель потока, 2 распределителя, система обратных, предохранительных и перепускных клапанов. Структурная схема рулевого управления представлена на рис. 1.

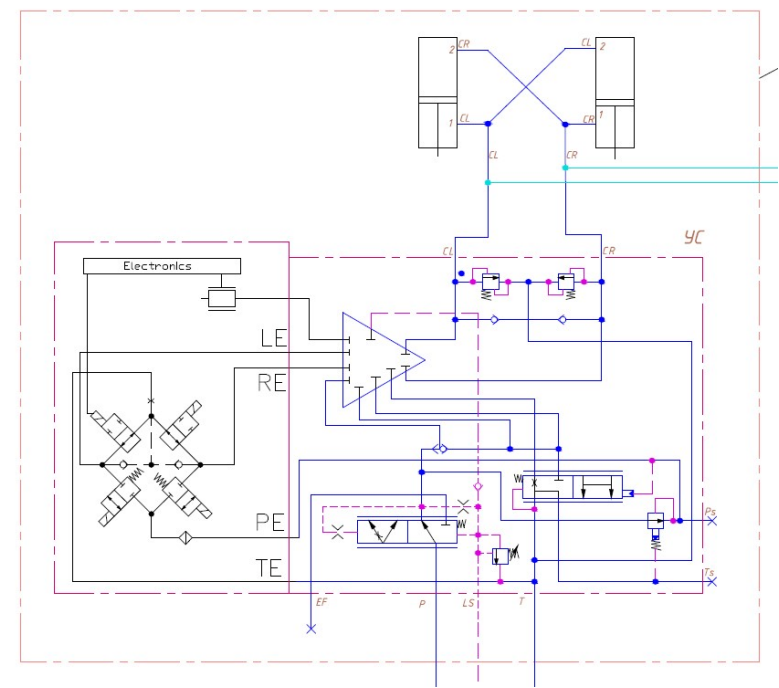

Рис. 1. Структурная гидравлическая схема системы рулевого управления ПТрМ

(собственная схема авторов)

Использование метода поворота складыванием позволяет применять колеса с шинами большого диаметра, широкого профиля и с низким внутренним давлением, которые, в свою очередь, обеспечивают хорошие тягово-сцепные качества, большие дорожные просветы; снижение давления на грунт при повышенных нагрузках на оси [8-10]. Конструктивные схемы механизмов поворота сочлененных машин показаны на рис. 2 [17].
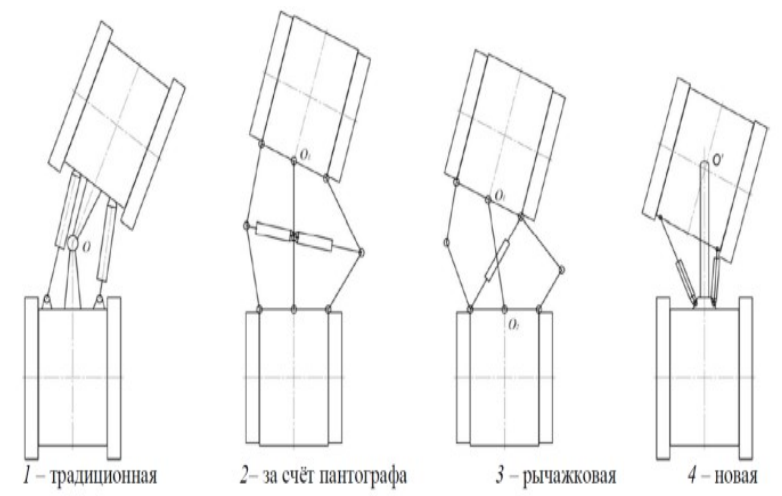

Рис. 2. Конструктивные схемы механизмов поворота сочлененных транспортных машин (схема Карташов А.Б, Газизулин Р.Л. [17])

\section{Материалы и методы}

При разработке конструкции узла сочленения лесной ПТрМ в качестве основной была выбрана традиционная схема механизма поворота сочлененной машины с наклонённым расположением силовых гидроцилиндров рулевого управления к продольной оси машины. Такая схема механизма поворота используется всеми зарубежными производителями ПТрМ.

При данной схеме механизма поворота радиус поворота по оси следа наружного колеса разрабатываемой ПТрМ составил 9,3 м, коридор поворота 4,1 м. Радиус и коридор поворота представлены на рис. 3.

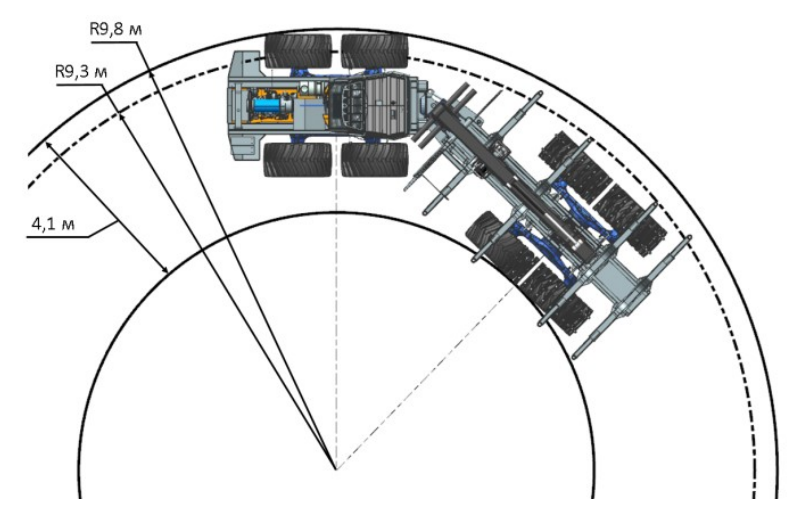

Рис. 3. Радиус и коридор поворота ПТрМ

(Результаты моделирования авторов)

Кинематический анализ узла сочленения ПТрМ представляет собой определение предельных углов складывания узла сочленения и хода силовых гидроцилиндров по разработанным электронным твердотельным моделям. Целью проведения кинематического анализа является подбор гидроцилиндров и определение размеров механизма сочленения. В качестве основного критерия для определения кинематической схемы является равенство объемов рабочей жидкости, которую необходимо перекачать для входа в поворот и выхода из поворота. Данное условие обеспечивается при условии равенства хода обоих гидроцилиндров при повороте [11].

Расположение цилиндров поворота звеньев гидросистемы РУ сочлененной колесной машины (КМ) относительно вертикального шарнира узла сочленения оказывает непосредственное влияние на параметры ее движения. Опыт проектирования 
подобных гидросистем показывает, что наиболее характерным их недостатком, вызванным неправильным расположением цилиндров поворота, является несоответствие угловых скоростей входа в поворот и выхода из поворота сочлененной КМ. В результате этого имеют место случаи, когда КМ, вошедшая в поворот, не может с достаточной интенсивностью выйти из него, что приводит к необходимости остановки и поворота звеньев на месте.

Важным является провести расчет момента сопротивления складыванию ПТрМ. Целью расчета является определение момента, потребного для складывания машины полной массы на месте на твердой опорной поверхности с высоким коэффициентом сцепления [12-15].

Расчет проводился при помощи программного комплекса автоматизированного анализа динамики систем тел. В данном комплексе колесная машина описывается в виде механической системы из набора твердых тел, соединенных шарнирами и силовыми связями. По такому описанию автоматически формируется система дифференциальноалгебраических уравнений, описывающих движение системы тел. Затем при помощи численного метода производится решение данных уравнений с получением временных реализаций кинематических и динамических параметров движения механической системы.

Внешний вид пространственной динамической модели лесной ПТрМ приведен на рис. 4.

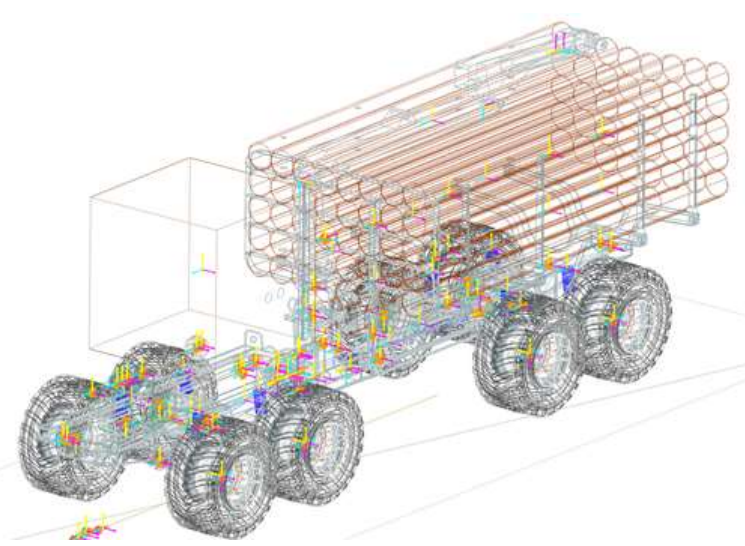

Рис. 4. Динамическая модель лесной ПТрМ

(Результаты моделирования авторов)
Модель имеет следующие особенности:

- все звенья динамической системы абсолютно жесткие;

- все колеса не заторможены и вращаются;

- трение в шарнирах отсутствует;

- груз (сортименты) смоделирован абсолютно жесткий единым телом;

- моделирование производилось для полностью груженой ПТрМ;

- дифференциалы в мостах не заблокированы (свободные).

Взаимодействие шин с опорной поверхностью описывалось при помощи полуэмпирической модели Пачейки MF-Tyre 6.1. Параметры модели для шины 750/55-26.5 приведены на рис. 5.

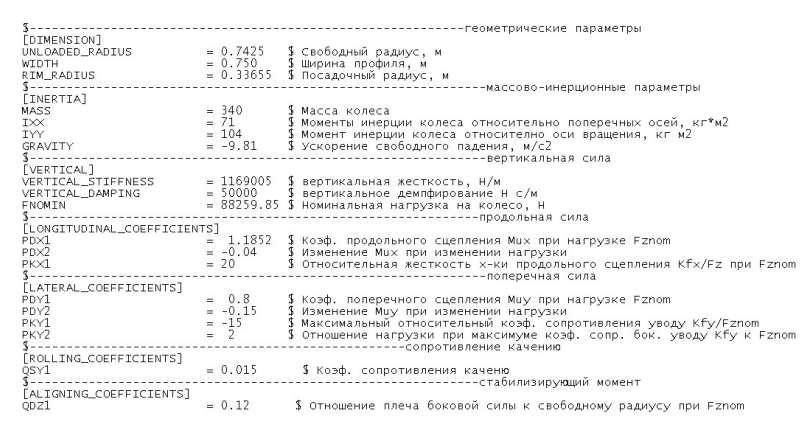

Рис. 5. Фрагмент файла с параметрами модели

MF-Tyre 6.1 для шины 750/55-26.5

(Файл параметров авторов)

Шарниры и силовые элементы, описывающие кинематику узла сочленения, показаны на рис. 6.

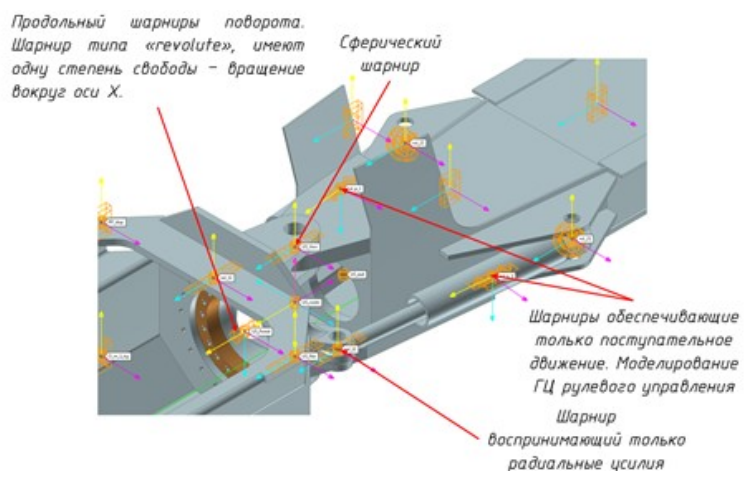

Рис. 6. Шарниры и силовые элементы узла сочленения (Результаты моделирования авторов)

\section{Результаты и обсуждение}

Результаты кинематического анализ узла сочленения показали, что основной причиной явле- 


\section{Технологии. Машины и оборудование}

ния когда сочлененная КМ, вошедшая в поворот, не может с достаточной интенсивностью выйти из него является разное количество жидкости, необходимое для входа в поворот и выхода из него, зависящее от расположения цилиндров относительно вертикального шарнира узла сочленения звеньев [16]. Т.е. необходимо обеспечить равный ход поршня, необходимый для входа в поворот и выхода из поворота.

Вторым критерием, является минимальное изменение плеч, на которых действуют гидроцилиндры. Более подробно данный вопрос рассмотрен в статье [17].

В результате анализа, была построена геометрическая схема узла сочленения, получены требуемые параметры силовых цилиндров и величины изменения плеч цилиндров. Данные результаты представлены на рис. 7 и 8, а также в табл. 1 и 2.

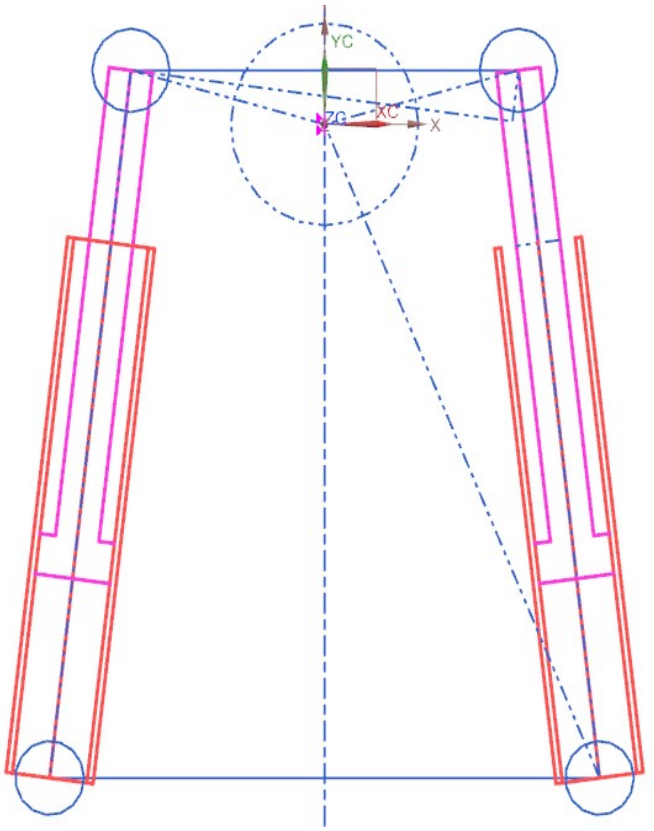

Рис. 7. Схема узла сочленения ПТрМ в статике (Результаты моделирования авторов)

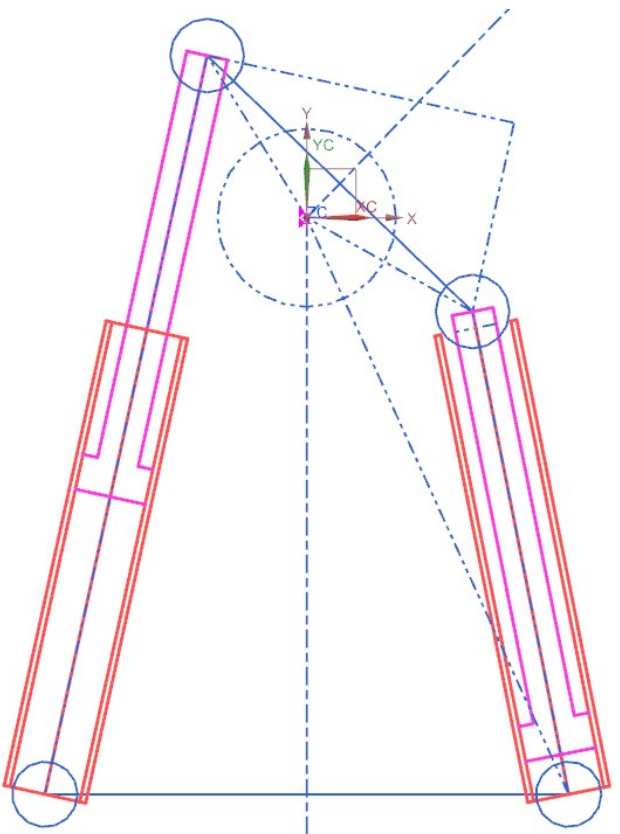

Рис. 8. Схема узла сочленения при складывании на угол 44 градуса (Результаты моделирования авторов)

Таблица 1

Параметры силовых гидроцилиндров (собственные результаты расчетов авторов)

\begin{tabular}{|c|c|c|c|c|c|}
\hline $\begin{array}{c}\text { Уго } \\
\text { л, } \\
\text { гра } \\
\text { д }\end{array}$ & \multicolumn{2}{|c|}{$\begin{array}{c}\text { Длина } \\
\text { гидилиндров, }\end{array}$} & \multicolumn{2}{|c|}{ Ход, мм } & $\begin{array}{c}\text { Разни } \\
\text { ца } \\
\text { хода, } \\
\%\end{array}$ \\
\cline { 2 - 5 } & $\begin{array}{c}\text { внеш } \\
\text { ний }\end{array}$ & $\begin{array}{c}\text { внутрен } \\
\text { ний }\end{array}$ & $\begin{array}{c}\text { внеш } \\
\text { ний }\end{array}$ & $\begin{array}{c}\text { внутрен } \\
\text { ний }\end{array}$ & \\
\hline 30 & 1213 & 894 & 155 & 164 & 5,5 \\
\hline 40 & 1256,5 & 845,6 & 198,5 & 212,4 & 6,5 \\
\hline 44 & 1272,4 & 828 & 214,4 & 230 & 6,8 \\
\hline
\end{tabular}

Таблица 2

Изменение плеч гидроцилиндров (собственные результаты расчетов авторов)

\begin{tabular}{|c|c|c|}
\hline $\begin{array}{c}\text { Угол } \\
\text { складывания, } \\
\text { град }\end{array}$ & $\begin{array}{c}\text { Плечо } \\
\text { внешнего ГЦ, } \\
\text { мм }\end{array}$ & $\begin{array}{c}\text { Плечо } \\
\text { внутреннего } \\
\text { ГЦ, мм }\end{array}$ \\
\hline 0 & 317,5 & 317,5 \\
\hline 6 & 311,8 & 320 \\
\hline 12 & 303,4 & 319,2 \\
\hline 18 & 292,5 & 314,5 \\
\hline 24 & 279,3 & 305,7 \\
\hline 30 & 264,1 & 292,5 \\
\hline 36 & 247,2 & 274,4 \\
\hline 42 & 228,6 & 251,2 \\
\hline 44 & 218,8 & 237,7 \\
\hline
\end{tabular}


При расчете момента сопротивления складывания машины моделирование производилось в течении 50 секунд, причем, первые 10 секунд гидроцилиндры рулевого управление не меняли длину, машина в течении этого времени приходила в состояние статического равновесия.

На рис. 9 показано равновесное положение лесной ПТрМ на горизонтальной поверхности. Стрелками показаны реакции на колесах. В табл. 3 приведено распределение нормальных реакций по колесам и осям, а также их суммарное значение.

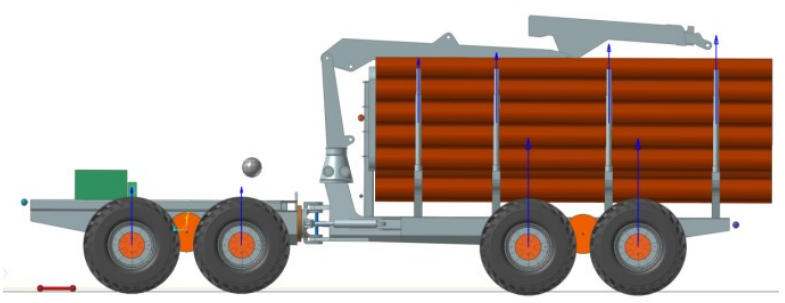

Рис. 9. Равновесие лесной ПТрМ на горизонтальной опорной поверхности

(Результаты моделирования авторов)

Таблица 3

Распределение нормальных реакций по колесам погрузочно-транспортной машины (собственные результаты расчетов авторов)

\begin{tabular}{|l|c|c|c|c|}
\hline & Ось 1 & Ось 2 & Ось 3 & Ось 4 \\
\hline $\begin{array}{l}\text { Левый } \\
\text { борт }\end{array}$ & 35783 & 35816 & 66816 & 66783 \\
\hline $\begin{array}{l}\text { Правый } \\
\text { борт }\end{array}$ & 35779 & 35812 & 66871 & 66838 \\
\hline $\begin{array}{l}\text { Сумма } \\
\text { для оси }\end{array}$ & 71562 & 71628 & 133687 & 133621 \\
\hline Сумма & \multicolumn{4}{|c|}{$410498 \mathrm{~N}(41859$ кг) } \\
\hline
\end{tabular}

Далее по заданному закону изменялась длина левого гидроцилиндра, при этом в нем автоматически формировалась движущая сила необходимая для поворота секций машины.

Результаты моделирования складывания секций машины на месте приведены на рис. 10-13.

На рисунке показаны кадры анимации, полученные при моделировании поворота ПТрМ на месте. Кадры соответствуют характерным положениям машины. Положение в момент времени
$\mathrm{T}=10$ с соответствуют начальному положению, в момент $\mathrm{T}=14 \mathrm{c}$ - максимальному углу складывания вправо, T $=34$ с - максимальному углу складывания влево, Т = 50 с - конечному положению.

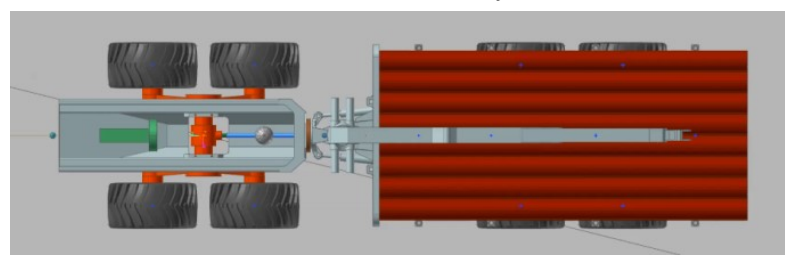

Рис. 10. Положения машины при повороте на месте, T $=10$ с (Результаты моделирования авторов)

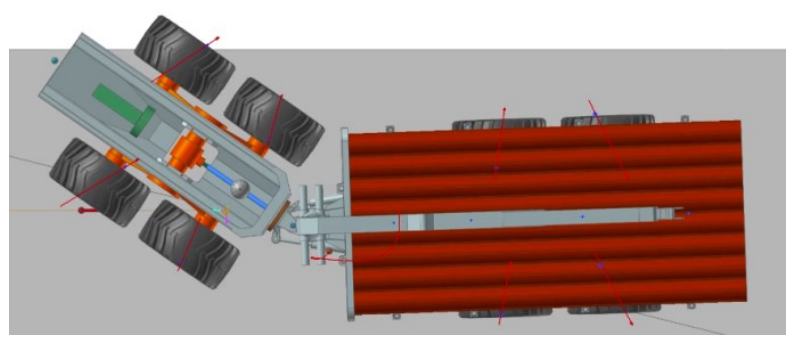

Рис. 11. Положения машины при повороте на месте, $\mathrm{T}=20 \mathrm{c}$

(Результаты моделирования авторов)

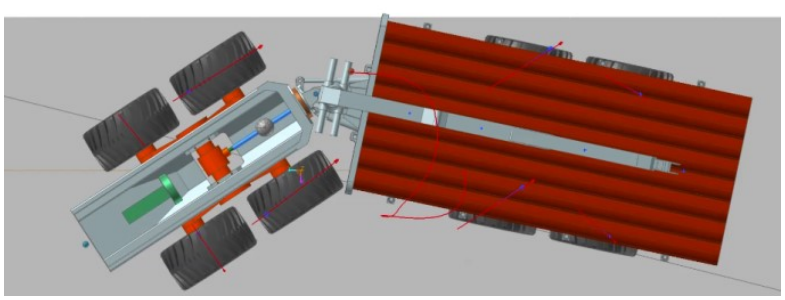

Рис. 12. Положения машины при повороте на месте, $\mathrm{T}=40 \mathrm{c}$

(Результаты моделирования авторов)

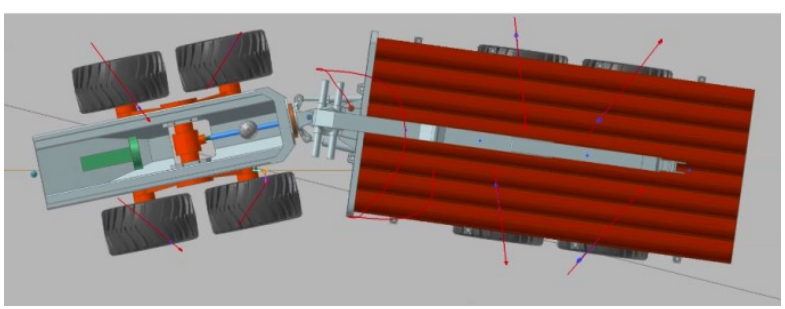

Рис. 13. Положения машины при повороте на месте, $\mathrm{T}=50 \mathrm{c}$

(Результаты моделирования авторов)

На рис. 14 представлен момент сопротивления складыванию лесной ПТрМ полной массы на месте на твердой опорной поверхности с высоким

\section{Лесотехнический журнал 4/2020}


коэффициентом сцепления. На рис. 15 представлен угол складывания секций рамы ПТрМ.

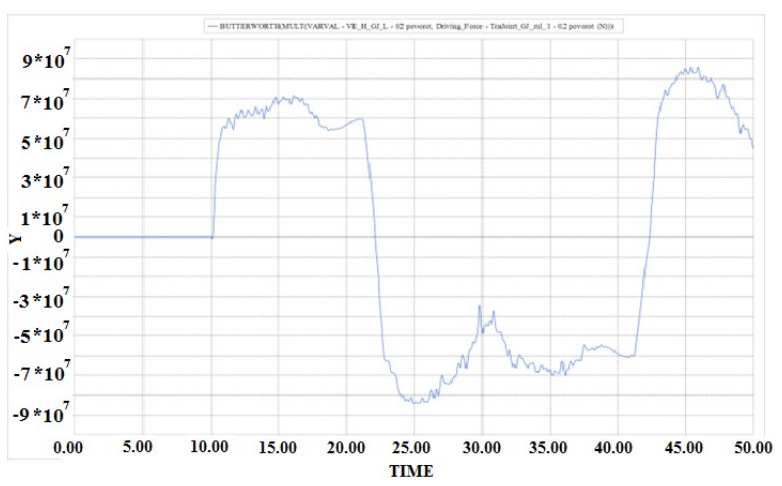

Рис. 14. Момент сопротивления складыванию лесной ПТрМ полной массы (Результаты моделирования авторов)

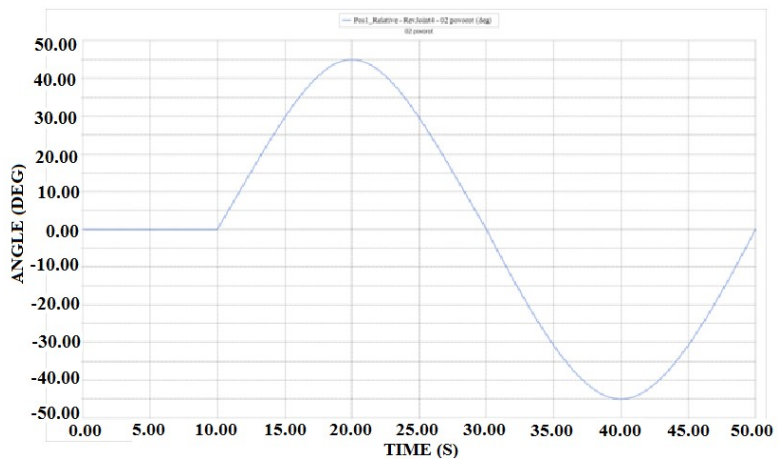

Рис. 15. Угол складывания секций рамы, град (Результаты моделирования авторов)

На рис. 16 и 18 представлены вертикальные нагрузки в пятне контакта колес переднего и заднего мостов, а на рис. 17 и 19 представлены боковые реакции в пятне контакта колес переднего моста и заднего мостов ПТрМ.

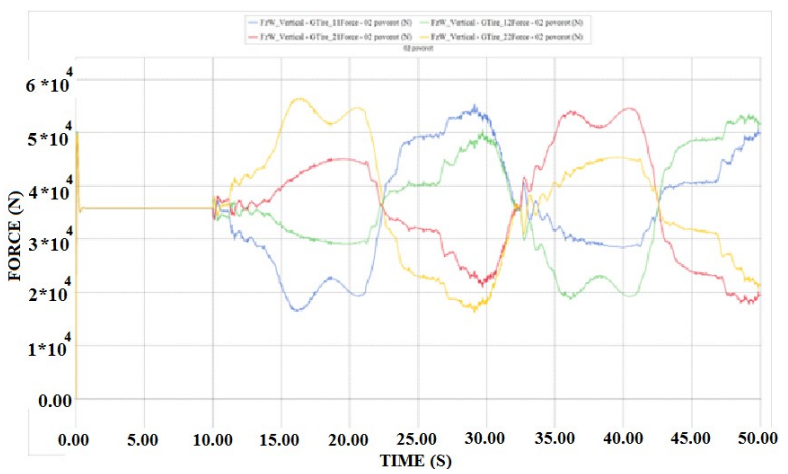

Рис. 16. Вертикальные нагрузки в пятне контакта колес переднего моста

(Результаты моделирования авторов)

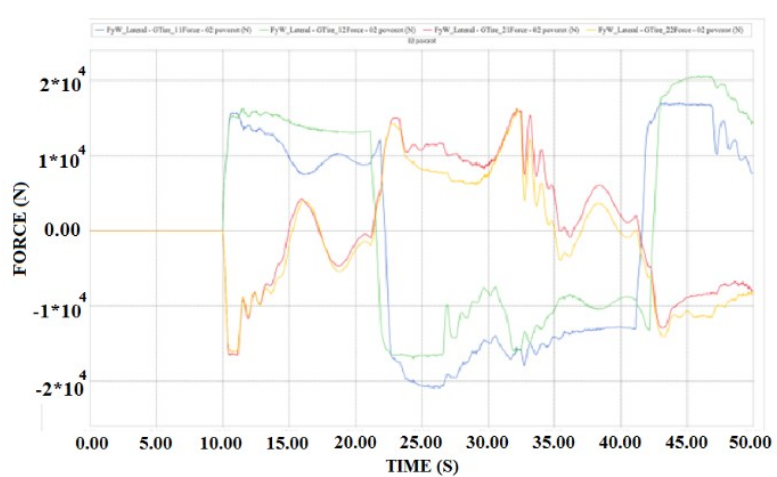

Рис. 17. Боковые реакции в пятне контакта колес переднего моста

(Результаты моделирования авторов)

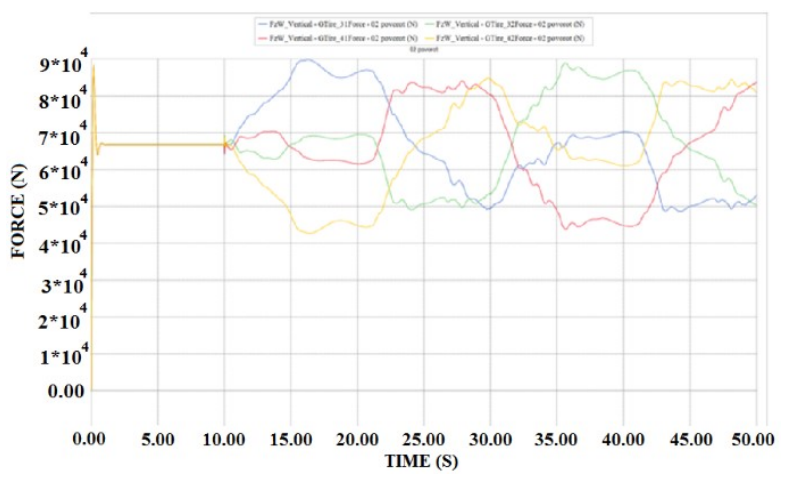

Рис. 18. Вертикальные нагрузки в пятне контакта колес заднего моста

(Результаты моделирования авторов)

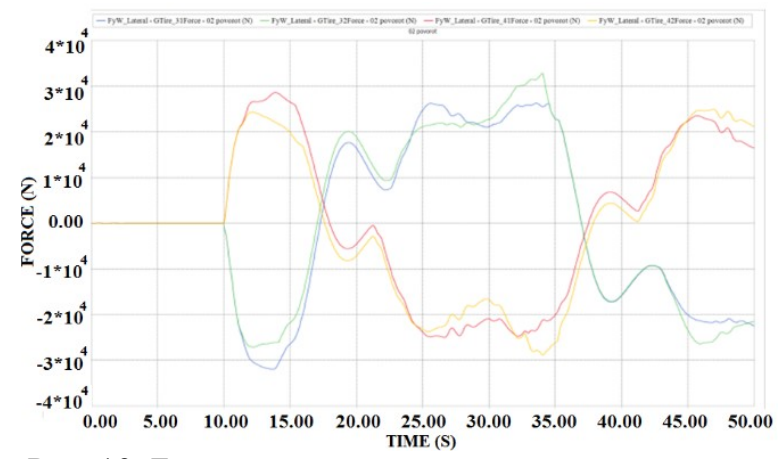

Рис. 19. Боковые реакции в пятне контакта колес заднего моста

(Результаты моделирования авторов)

\section{Выводы}

По результатам кинематического анализа узла сочленения установлено, что максимальный конструктивно реализуемый угол складывания несущей системы составил 44 градуса. При склады- 
вании узла сочленения на 44 градуса происходит упор ограничителей в раму. Разница в ходах поршней ГЦ, составила 15,6 мм для угла складывания 44 градуса, или $6,8 \%$ от хода. Изменение плеч составило 99 мм, для внешнего цилиндра и 80 мм для внутреннего цилиндра.
Определен момент сопротивления складыванию ПТрМ полной массы на месте на твердой опорной поверхности с высоким коэффициентом сцепления. Представлены вертикальные нагрузки в пятне контакта колес переднего и заднего мостов, а также боковые реакции в пятне контакта колес переднего и заднего мостов.

\section{Благодарности}

Работа выполнена в МГТУ им. Н.Э. Баумана при финансовой поддержке Министерства науки и высшего образования Российской Федераџии в рамках соглашения №075-11-2019-030 от 22 ноября 2019 г.

\section{Библиографический список}

1. Клубничкин, В.Е. Краткий анализ тенденций развития лесозаготовительных машин / В.Е. Клубничкин, Е.Е. Клубничкин, А.Б. Карташов // Труды НГТУ им. Р.Е. Алексеева. - 2020. - № 3(130). - С. $93-102$.

2. Голякевич, С.А. Экспериментальные исследования нагруженности несущих конструкций шарнирносочлененных лесозаготовительных машин / С.А. Голякевич, А.Р. Гороновский // Труды БГТУ. Лесная и деревообрабатывающая промышленность. - 2012. - № 2. - С. 15-17.

3. Ringdahl, O. Potentials of Possible Machine Systems for Directly Loading Logs in Cut-to-Length Harvesting / O. Ringdahl, T. Hellström, O. Lindroos // Canadian Journal of Forest Research. - 2012. - vol. 42, no. 5. - pp. 970985. DOI: $10.1139 / \mathrm{x} 2012-036$

4. Козьмин, С.Ф. Исследование компоновки лесных колесных тракторов с шарнирной рамой конструкции ЛТА. Лесные тракторы МТ3-82Л и Т-150КЛ с колесной формулой 6х6 и их модификации: учеб. пособие / С.Ф. Козьмин [и др.] ; М-во образования и науки РФ, ГОУ ВПО «СПбГЛТА» - Санкт-Петербург, 2011. - 96 с.

5. Golyakevich, S.A. Evaluation of Loading Dynamics and Fatigue Life for a Forwarder Half-Frame Articulation / S.A. Golyakevich, A.R. Goronovskii // Journal of Machinery Manufacture and Reliability. - 2017. - vol. 46, iss. 5. - pp. 463-471. DOI: 10.3103/S1052618817050077

6. Голякевич, С.А. Эксплуатационные испытания шарниров сочленения полурам лесозаготовительных машин ПО "МТЗ" / С.А. Голякевич, В.А. Коробкин, М.К. Асмоловский // Труды БГТУ. Лесная и деревообрабатывающая промышленность. - 2011. - № 2. - C. 122-126.

7. Proto, A.R. Factors Affecting Forwarder Productivity / A.R. Proto, G. Macrì, R. Visser, H. Harrill, D. Russo, G. Zimbalatti // European Journal of Forest Research. - 2018. - vol. 137, iss. 2. - pp. 143-151. DOI: 10.1007/s10342017-1088-6

8. Беляков, В.В. Полотно пути транспортно-технологических машин (справочные материалы к теории «машина-местность») учебник / под ред. В.В. Белякова, А.А. Куркина ; М-во образования и науки РФ, ГОУ ВПО «НГТУ им. Р.Е. Алексеева». - Нижний Новгород, 2014. - 447 с.

9. Allman, M. Soil compaction of various central european forest soils caused by traffic of forestry machines with various chassis / M. Allman, M. Jankovský, V. Messingerová, Z. Allmanová, M. Ferenčík // Forest Systems. 2015. - № 24(3).

10. Klubnichkin, E.E. Theoretical research of soil packing by timber harvester running gear / E.E. Klubnichkin, V.E. Klubnichkin, G.O. Kotiev // IOP Conference Series: Materials Science and Engineering. - 2018. - C. 012025.

11. Полунгян, А.А. Проектирование полноприводных колесных машин: учеб. для вузов / А.А. Полунгян, Б.А. Афанасьев, Н.Ф. Бочаров [и др.] ; М-во образования и науки РФ, ГОУ ВПО «МГТУ им. Н. Э. Баумана». Москва, Т. 1. 1999. - 488 с. 
12. Редкозубов, А.В. Определение характеристик микропрофиля дорог, предназначенных для движения транспортно-технологических машин / В.С. Макаров, К.О. Гончаров, В.В. Беляков, Д.В. Зезюлин, А.М. Беляев, А.В. Папунин, А.В. Редкозубов // Современные проблемы науки и образования. - 2012. - № 5. - С. 113.

13. Laughery, S. Bekker's Terramechanics Model for Off-Road Vehicle Research / S. Laughery, G. Gerhart, R. Goetz // - 1990 .

14. Wong, J.Y. Terramechanics and Off-Road Vehicle Engineering, / J.Y. Wong. - Second Edition. - Oxford: Elsevier, 2010. - 488 p. - ISBN: 978-0-7506-8561-0.

15. Klubnichkin, V. Researching rolling resistance of the wheeled forestry tractor at skidding / V. Klubnichkin, E. Klubnichkin, M. Podrubalov, V. Makarov // IOP Conference Series: Materials Science and Engineering. - 2019. - C. 012003 .

16. Анисимов, Г.М. Испытания лесосечных машин: учеб. пособие / Г.М. Анисимов, А.М. Кочнев ; $M-в о$ образования и науки РФ, ГОУ ВПО «СПбГЛТА». - Санкт-Петербург, 2008. - 488 с. - ISBN 978-5-9239-0111-5

17. Карташов, А.Б. Разработка вездеходных транспортных средств с шарнирно сочлененной несущей системой на базе серийного грузового автомобиля / А.Б. Карташов, Р.Л. Газизулин // Инженерный вестник. 2016. - №12. - C. 10.

\section{References}

1. Klubnichkin V.E., Klubnichkin E.E., Kartashov A.B. Kratkiy analiz tendentsiy razvitiya lesozagotovitel'nykh mashin [Brief analysis of trends in the development of logging machines]. Trudy NGTU im. R.E. Alekseeva [Proceedings of NSTU im. R.E. Alekseeva]. 2020, № 3(130), pp. 93-102.

2. Golyakevich S.A., Goronovskiy A.R. Eksperimental'nye issledovaniya nagruzhennosti nesushchikh konstruktsiy sharnirno-sochlenennykh lesozagotovitel'nykh mashin [Experimental studies of the loading of load-bearing structures of articulated logging machines]. Trudy BGTU. Lesnaya i derevoobrabatyvayushchaya promyshlennost' [Proceedings of BSTU. Timber and woodworking industry]. 2012, № 2, pp. 15-17.

3. Ringdahl O., Hellström T., Lindroos O. Potentials of Possible Machine Systems for Directly Loading Logs in Cut-to-Length Harvesting. Canadian Journal of Forest Research, 2012, vol. 42, no. 5. - pp. 970-985. doi: $10.1139 / \mathrm{x} 2012-036$

4. Koz'min, S.F. Issledovanie komponovki lesnykh kolesnykh traktorov s sharnirnoy ramoy konstruktsii LTA. Lesnye traktory MTZ-82L i T-150KL s kolesnoy formuloy 6kh6 i ikh modifikatsii [Study of the layout of forest wheeled tractors with an articulated frame of the LTA design. Forest tractors MTZ-82L and T-150KL with 6x6 wheel arrangement and their modifications]. Sankt-Peterburg: SPbGLTA, 2011. 96 p.

5. Golyakevich S.A. Goronovskii A.R. Evaluation of Loading Dynamics and Fatigue Life for a Forwarder HalfFrame Articulation. Journal of Machinery Manufacture and Reliability, 2017. vol. 46, iss. 5. - pp. 463-471. doi: 10.3103/S1052618817050077

6. Golyakevich S.A., Korobkin V.A., Asmolovskiy M.K. Ekspluatatsionnye ispytaniya sharnirov sochleneniya poluram lesozagotovitel'nykh mashin PO "MTZ" [Operational tests of the hinges of the articulation of the semi-frames of the logging machines PO "MTZ"] Trudy BGTU. Lesnaya i derevoobrabatyvayushchaya promyshlennost' [Proceedings of BSTU. Timber and woodworking industry]. 2011, № 2. pp. 122-126.

7. Proto, A.R., Macrì G., Visser R., Harrill H., Russo D., Zimbalatti G. Factors Affecting Forwarder Productivity. European Journal of Forest Research, 2018. vol. 137, iss. 2. - pp. 143-151. doi: 10.1007/s10342-017-1088-6

8. Belyakov V.V., Kurkin A.A. Polotno puti transportno-tekhnologicheskikh mashin (spravochnye materialy $k$ teorii «mashina-mestnost'») [Tracks of transport and technological machines (reference materials to the theory of "machine-locality")]. Nizhniy Novgorod: NGTU im. R.E. Alekseeva, 2014. 447 p.

9. Allman M., Jankovský M., Messingerová V., Allmanová Z., Ferenčík M. Soil compaction of various central European forest soils caused by traffic of forestry machines with various chassis. Forest Systems, 2015, № 24(3). 
10. Klubnichkin E.E., Klubnichkin V.E., Kotiev G.O. Theoretical research of soil packing by timber harvester running gear. IOP Conference Series: Materials Science and Engineering, 2018, C. 012025.

11. Polungyan A.A., Afanas'ev B.A., Bocharov N.F., eds. Proektirovanie polnoprivodnykh kolesnykh mashin [Design of all-wheel drive vehicles]. Moscow: MGTU im. N. E. Baumana, T. 1. 1999. 488 p.

12. Redkozubov A.V., Makarov V.S., Goncharov K.O., Belyakov V.V., Zezyulin D.V., Belyaev A.M., Papunin A.V. Opredelenie kharakteristik mikroprofilya dorog, prednaznachennykh dlya dvizheniya transportnotekhnologicheskikh mashin [Determination of the characteristics of the micro-profile of roads intended for the movement of transport and technological machines]. Sovremennye problemy nauki i obrazovaniya [Modern problems of science and education]. 2012, № 5, pp. 113.

13. Laughery S., Gerhart G., Goetz R. Bekker's Terramechanics Model for Off-Road Vehicle Research. 1990.

14. Wong J.Y. Terramechanics and Off-Road Vehicle Engineering. Second Edition. Oxford: Elsevier, 2010. 488 p.

15. Klubnichkin V., Klubnichkin E., Podrubalov M., Makarov V. Researching rolling resistance of the wheeled forestry tractor at skidding. IOP Conference Series: Materials Science and Engineering, 2019, C. 012003.

16. Anisimov G.M., Kochnev A.M. Ispytaniya lesosechnykh mashin [Testing of cutting machines]. SanktPeterburg: SPbGLTA, 2008. 488 p.

17. Kartashov A.B., Gazizulin R.L. Razrabotka vezdekhodnykh transportnykh sredstv s sharnirno sochlenennoy nesushchey sistemoy na baze seriynogo gruzovogo avtomobilya [Development of all-terrain vehicles with an articulated supporting system based on a serial truck]. Inzhenernyy vestnik [Engineering bulletin]. 2016, №12, pp. 10.

\section{Сведения об авторах}

Клубничкин Владислав Евгеньевич - кандидат технических наук, доцент, доцент кафедры «Транспортнотехнологические средства и оборудование лесного комплекса» Мытищинского филиала ФГБОУ ВО «Московский государственный технический университет имени Н.Э. Баумана», г. Мытищи, Российская Федерация; e-mail: vklubnichkin@gmail.com.

Клубничкин Евгений Евгеньевич - кандидат технических наук, доцент, доцент кафедры «Транспортнотехнологические средства и оборудование лесного комплекса» Мытищинского филиала ФГБОУ ВО «Московский государственный технический университет имени Н.Э. Баумана», г. Мытищи, Российская Федерация; e-mail: klubnichkin@mgul.ac.ru.

Горбунов Алексей Юрьевич - ведущий инженер отдела НИИСМ 3-2, ФГБОУ ВО «Московский государственный технический университет имени Н.Э. Баумана», г. Москва, Российская Федерация; е-mail: gorbunov@bmstu.ru.

Дручинин Денис Юрьевич - кандидат технических наук, доцент, заведующий кафедрой механизации лесного хозяйства и проектирования машин ФГБОУ ВО «Воронежский государственный лесотехнический университет имени Г.Ф. Морозова», г. Воронеж, Российская Федерация; e-mail: druchinin.denis@rambler.ru.

\section{Information about authors}

Klubnichkin Vladislav Evgenyevich - PhD (Engineering), Associate Professor, Associate Professor of transport and technological means and equipment of the forest complex department, Mytishi branch of FSBEI HE "Bauman Moscow State Technical University", Mytishi, Russian Federation; e-mail: vklubnichkin@gmail.com.

Klubnichkin Evgeny Evgenyevich - PhD (Engineering), Associate Professor, Associate Professor of transport and technological means and equipment of the forest complex department, Mytishi branch of FSBEI HE "Bauman Moscow State Technical University", Mytishi, Russian Federation; e-mail: klubnichkin@mgul.ac.ru.

Gorbunov Aleksey Yuryevich - leading design engineer of NIISM 3-2 department, FSBEI HE "Bauman Moscow State Technical University", Moscow, Russian Federation; e-mail: gorbunov@bmstu.ru.

Druchinin Denis Yuryevich - PhD (Engineering), Associate Professor, Head of the Department of Forestry Mechanization and Machine Design, FSBEI HE "Voronezh State University of Forestry and Technologies named after G.F. Morozov", Voronezh, Russian Federation; e-mail: druchinin.denis@rambler.ru. 